\title{
Twenty year follow up of patients in the Medical Research Council trial of anticoagulants in acute myocardial infarction
}

\author{
A S DOUGLAS, LINDA COLWELL, GEOFFREY ROSE
}

From the Department of Medicine, Aberdeen Royal Infirmary and The Department of Epidemiology, London School of Hygiene and Tropical Medicine

SUMMARY A 20 year follow up of 1330 patients in the Medical Research Council trial of short term anticoagulant treatment in myocardial infarction showed no long term benefits; but it provided interesting data on the outcome in such patients. Sixteen per cent of the patients were alive 20 years later. The excess mortality rate in trial participants over that expected for England and Wales as a whole declined rapidly after the early months, but some excess persisted throughout the follow up. Three quarters of all the deaths were from coronary heart disease; $70 \%$ of these coronary deaths occurred after the patients had left hospital. This finding emphasises the importance of secondary prevention.

There has been little systematic study of the long term outcome after myocardial infarction. ${ }^{1-7} \mathrm{~A}$ follow up of patients in the Medical Research Council trial of anticoagulants in acute myocardial infarction, ${ }^{8}$ undertaken in order to check for any late effects of treatment, offered an opportunity also to examine survival over a 20 year period in a welldocumented series of patients who had been discharged after a month of treatment. This seems to be the longest systematic follow up of survivors of myocardial infarction.

\section{Patients and methods}

Between 1963 and 1966 a total of 1416 patients with myocardial infarction (all ages, both sexes) entered the Medical Research Council trial and were randomly allocated to four weeks' treatment with phenindione, either full dosage or $1 \mathrm{mg}$ daily. Their average age was 58 years; $77 \%$ were men. One hundred and fifteen patients in the high dose group died while they were in the trial compared with 129 in the low dose group; this difference was not statistically significant. Thromboembolism was significantly less

Requests for reprints to Professor Geoffrey Rose, London School of Hygiene and Tropical Medicine, Keppel Street, London WC1E 7HT.

Accepted for publication 18 December 1986 common in the high dose group than in the low dose group $(5 \%$ vs $11 \%$ ).

With the help of the National Health Service central registers in Southport and Edinburgh and the Social Security office in Newcastle we were able to trace $94 \%$ of the patients (668 from the high dose group and 662 from the low dose group). Of these, $1111(84 \%)$ had died and their death certificates have been made available.

The survival experience of the patients was compared with an expected survival curve based on the England and Wales life table for $1971,{ }^{9}$ and the application of appropriate age specific mortality rates to a cohort of the same age and sex distribution as the patients in the study. Eleven patients entered the trial more than once; their survival experience has been reckoned from the first attack.

\section{Results}

Figure 1 shows the 20 year progress of coronary heart disease mortality for the trial's two groups: the differences are small and within chance limits. Results for specific causes of death were also similar in the two groups.

Despite having suffered a major acute episode in a dangerous chronic disease, $219(16 \%)$ patients are alive 20 years later. For those who survived for 28 days the 20 year survival rate was $20 \%$; however, 


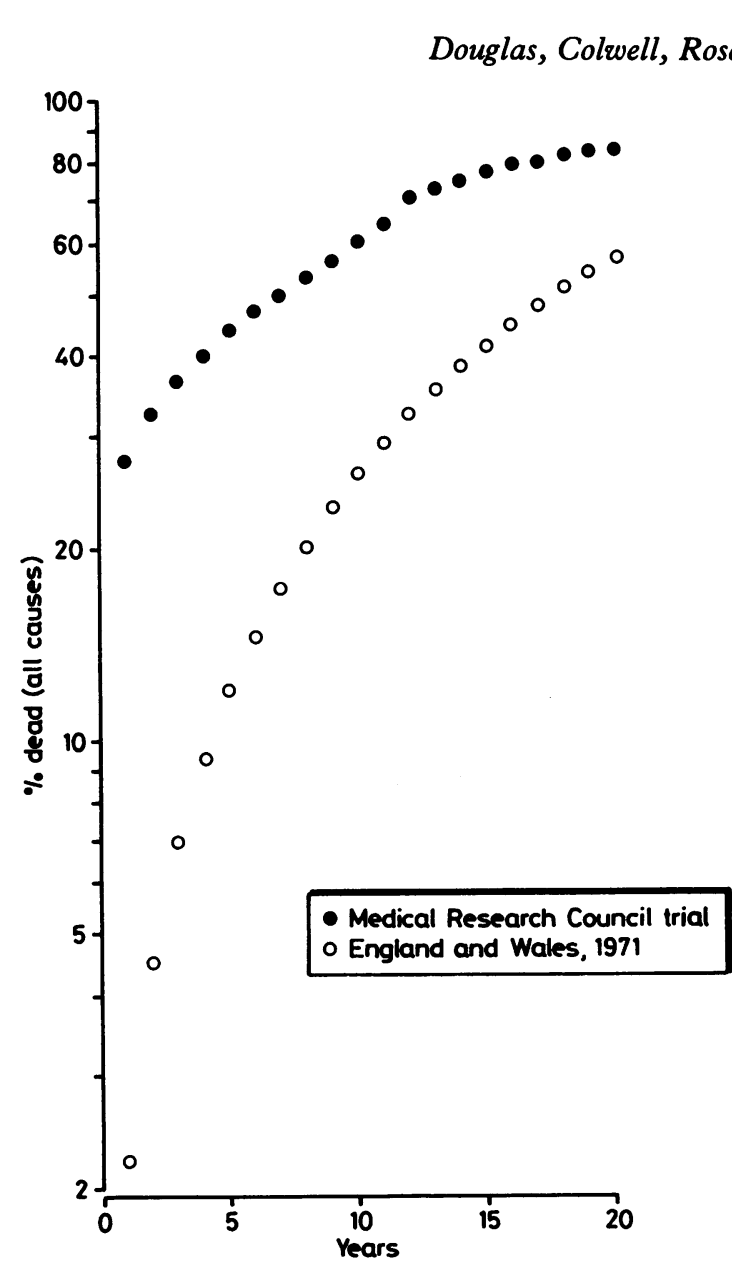

hospital with myocardial infarction

\begin{tabular}{ll}
\hline Status & Number (\%) \\
\hline Alive & $219(16)$ \\
Dead: & $223(17)$ \\
Coronary heart disease: in hospital & $629(47)$ \\
& $41(3)$ \\
Stroke & $50(4)$ \\
Other cardiovascular disease & $31(2)$ \\
Lung cancer & $48(4)$ \\
Other respiratory disease & $33(2)$ \\
Other cancer & $12(1)$ \\
Diabetes mellitus & $30(2)$ \\
Other cause & $14(1)$ \\
Cause unknown & 86 \\
\hline Lost to follow up & \\
\hline
\end{tabular}

for age and sex. Clearly the worse experience of the patients arises chiefly in the first five years, and especially the first year. The excess mortality in relation to the general population is 2.3 in the first 10 years and 1.4 in the next 10 years.

Survival was less likely in women than men $(20$ year survival $13 \cdot 2 \%$ compared with $17 \cdot 4 \%$ ), but they were an older group (average age at entry 62 years compared with 56 years for men).
Fig 2 Cumulative actuarial mortality from all causes in study patients compared with expected mortality according to England and Wales rates (semilogarithmic scale).

\section{Discussion}

The trial did not identify any significant reduction in coronary events during the short period of anticoagulant treatment, despite the convincing evievents; and it is therefore not surprising that no long term benefit has emerged. A subsequent pooling of results from six randomised trials found an overall significant reduction of $21 \%$ in the acute case fatality. ${ }^{10}$ Thus the difference in the Medical Research Council trial result could be due to chance.

As far as we know, 20 years is the longest period during which survivors of hospital admission for myocardial infarction have been studied; the cases were all well documented and had no major criteria for exclusion. Success in tracing $94 \%$ of the patients dence of a short term reduction in thromboembolic 
20 years later demonstrates the particular advantages enjoyed by investigators who study the long term outcome in patients in the United Kingdom, even where such a long follow up was not planned at the outset.

Several important conclusions follow from the findings. The first is that for a substantial proportion of patients suffering a myocardial infarction, outcome is favourable: of those who survived the acute attack one in five are alive 20 years later. The average age of these patients was already 58 years at entry to the study. Their excess risk declined progressively with increasing interval from the attack, and after 10 years it was small. In interpreting the changing slopes of the survival curves it must, however, be remembered that they refer to a changing study population. The declining risk reflects not only the lengthening interval from the attack but also the progressive disappearance of those who were older at the time of the attack. Those who survive are, however, getting older and other things being equal this would increase their risk of death.

Norris's group have shown that impairment of left ventricular function influences long term as well as short term prognosis, ${ }^{1}$ implying that among those with lesser degrees of myocardial injury the long term prognosis is even better than our figures suggest.

The second important conclusion is that myocardial infarction is a chronic and protracted disease. In our study of hospital patients with myocardial infarction more than $70 \%$ of all the deaths attributed to coronary heart disease occurred more than a month after hospital admission. This illustrates how the acute care of coronary patients touches on only a small part of the total problem, and it emphasises the much greater potential importance of secondary prevention. In this series, for example, a $10 \%$ reduction in coronary mortality after discharge would have been equivalent to a $25 \%$ reduction during the period in hospital. After the attack there is a rapid decline in the death rate of these patients; but this should not distract attention from the fact that most of the deaths occur after patients have left hospital and that such patients continue to be at high risk.

This work was supported by a grant from the Medical Research Council.

\section{References}

1 Merrilees MA, Scott PJ, Norris RM. Prognosis after myocardial infarction: results of 15 year follow up. Br Med J 1984;288:356-9.

2 Weinblatt E, Shapiro S, Frank CW, Sager RV. Prognosis of men after myocardial infarction: mortality and first recurrence in relation to selected parameters. Am J Public Health 1968;58:1329-47.

3 Pell S, D'Alonzo CA. Immediate mortality and five year survival of employed men with a first myocardial infarction. N Engl J Med 1964;270:915-22.

4 Honey GE, Truelove SC. Prognostic factors in myocardial infarction. Lancet 1957;i:1155-61, 1209-12.

5 Cole DR, Smgian EB, Katz LN. The long term prognosis following myocardial infarction and some factors which affect it. Circulation 1954;9:321-34.

6 Katz LN, Mills GY, Cisneros F. Survival after acute infarction. Arch Intern Med 1949;84:305-20.

7 Levine SA, Rosenbaum FF. Prognostic value of various clinical and electrocardiographic features of acute myocardial infarction: ultimate prognosis. Arch Intern Med 1941;68:1215-31.

8 Report of the Working Party on Anticoagulant Therapy in Coronary Thrombosis to the Medical Research Council 1969. Assessment of short-term anticoagulant administration after cardiac infarction. Br Med J 1969;i:335-42.

9 The Registrar General's Decennial Supplement for England and Wales. Life tables 1970-1972. (Series DS no. 2.) London: HMSO, 1979.

10 Chalmers TC, Matta RJ, Smith H, Kunzler AM. Evidence favoring the use of anticoagulants in the hospital phase of acute myocardial infarction. $N$ Engl J Med 1977;297:1091-6. 